\title{
Good for people can be good for business: the convergence of opportunities for delivering basic energy to low-income households in developing countries
}

\author{
Marlett Balmer \\ PhD candidate, Faculty of Engineering, Built Environment and Information Technology, University of Pretoria
}

David Hancock

Programme Manager for Biomass Energy Conservation (ProBEC) Programme

\begin{abstract}
Energy poverty affects more than $40 \%$ of the world's population. Fuels and appliances used by low-income groups have been of low-quality, expensive, non-durable and have posed serious health and safety risks to users. Energy transition theories, most noteably the energy ladder model, have postulated a gradual but complete move away from traditional, mostly biomass energy sources towards modern energy sources. Evidence however, increasingly indicates that the process did not happen as anticipated. This paper argues that energy transition from biomass fuels to full electricity use will not take place in SADC countries due to economic circumstances, increases in commercial fuel prices and the deficit in power generation capacity in the region. It further argues that wood fuel, traditionally regarded as a lower order fuel, is actually a renewable energy source that can meet the energy needs of rural people sustainably, if managed correctly. The paper suggests a re-evaluation of the value of wood fuel - from a low value fuel associated with poverty and degradation to a high value, renewable energy fuel, supplying much needed energy in a potentially sustainable manner. The paper outlines a convergence of a number of external conditions and opportunities which may alter household energy supply, making it possible for households to benefit from high quality, small quantities of electricity for lighting and communication purposes and extremely high quality, affordable appliances utilising biomass energy sources to supply thermal energy requirements.
\end{abstract}

Keywords: household energy, biomass energy, energy efficient appliances

\section{Introduction}

Energy poverty remains a challenge in developing countries, impacting on the environment, health, security and well-being of an estimated 3 billion people. Around 2.64 billion people, or $40 \%$ of the world's population, lack modern fuels for cooking and heating while 1.6 billion have no access to electricity, three-quarters of them living in rural areas (Litovsky, 2007). In practical terms, energy poverty means poor households do not have access to adequate and appropriate energy sources to service their most basic energy needs. These households meet most of their energy needs through biomass energy sources while small amounts of commercial energy is used mainly when it is accessible and affordable.

Low-income households in developing countries also display distinct energy use patterns where thermal energy requirements (such as cooking, space heating and water heating) are traditionally met with biomass sources while small quantities of electricity is used to supply energy for lighting, cell phone charging, radio and television. This pattern of energy use is also referred to as multiple fuel use, meaning that households use a range of appliances and fuels at the same time or interchangeably. According to Prasad (2006) some households are complete multiple fuel users and they use different fuels for different energy end-uses, while other households switch from one fuel to another for the same end-use, for example, from gas to paraffin or gas to fuel wood for cooking. Prasad (2006) outlines that the multiple fuel use model emphasises the fact that households do not drop one fuel when they start using a more efficient one, but retain a number of fuels over a wide range of income levels. 
Traditionally, appliances used by low-income groups are inefficient, unsafe and non- durable. For example, in a 2003 investigation by the Paraffin Safety Association in South Africa, the 9 best selling paraffin stoves were tested and none were found to pass basic safety regulations (Kruger, 2006). Designers and developers attempting to provide better quality products are faced with the challenge of producing improved appliances at an affordable price for a poor target market. Improved appliances also have to compete with existing, bad quality but more affordable appliances already in the market. Caught between the demands in terms of performance, aesthetics and functionality of the target market, the high material and production costs, the lack of supply and distribution chains, inadequate marketing and awareness raising budgets and the unwillingness to invest in the technology and/or inability of the target market to afford the product, designers have had little success in penetrating the market and delivering products that sell like the proverbial 'hot cakes'.

The paper will argue that energy transition from biomass fuels to full electricity use will not take place in $\mathrm{SADC}^{1}$ countries due to economic circumstances, increases in commercial fuel prices and the deficit in power generation capacity in the region. It will further argue that wood fuel, traditionally regarded as a lower order fuel, is actually a renewable energy source that can meet the energy needs of rural people sustainably, if managed correctly. The paper therefore, suggests a re-evaluation of the value of wood fuel - from a low value fuel associated with poverty and degradation to a high value, renewable energy fuel, supplying much needed energy in a potentially sustainable manner. The paper will lastly, attempt to outline a convergence of a number of external conditions and opportunities which may alter household energy supply, making it possible for households to benefit from high quality, small quantities of electricity for lighting and communication purposes, and extremely high quality, affordable appliances utilising biomass energy sources to supply thermal energy requirements.

\section{Background}

The ruling post-Second World War paradigm of modernisation gave rise to the theory of the existence of an energy ladder, used to explain the transition in fuel consumed by households (Price et al., 2006). Clancy (2004) (after Hosier and Kipondya, 1993) explains that the energy ladder concept is based loosely on the economic theory of household behaviour and the assumption that modern fuels (electricity and gas) are normal economic goods and the traditional fuels (such as wood, dung and crop residues) are inferior goods. It was therefore, expected that as household income increases, there will be a switch from relying on traditional fuels to modern fuels. By extension, higher income households will make greater use of modern fuels than low-income households do. According to the energy ladder, households will progress from the lower order fuels, up the ladder to more progressively modern fuels such as coal and gas, to the top rung of the ladder where they will use electricity. The movement up the ladder would be linear, simple, quick and easy and determined by increased levels of income and increased levels of urbanisation (Pachauri and Spreng, 2003).

However, evidence increasingly indicates that the process did not happen as anticipated. In reality, wood fuel is becoming scarcer with localised regional wood deficits and deforestation causing rapidly rising prices in a commodity that was traditionally regarded as 'free'. For example, in an analysis to investigate trends in wood fuel use in Lesotho, Balmer (2007) found increases in time spent collecting wood fuel, distances walked to collect wood as well as price increases.

Apart from the increased pressure on the biomass resource, significant price increases have also been experienced for commercial fuels such as paraffin, gas and electricity. For example, the paraffin price has increased by $87 \%$ since 2007 in South Africa while Eskom, the South African electricity utility, applied for a $53 \%$ tariff hike to be effected from April 2008 (Pringle, 2008). Continued price increases of commercial fuels make it more difficult for low-income households to use commercial fuels at a significant rate.

Commercial fuels are not only expensive but often inaccessible to low-income households, especially electricity. According to The World Bank (2008a), only $24 \%$ of the population in subSaharan Africa have access to electricity compared to $40 \%$ in other low-income countries. Moreover, electricity consumption in the region is significantly lower than in other regions. However, it is not only low levels of access that hampers electricity use. The entire generation capacity of the 48 countries of sub-Saharan Africa at 63 gigawatts (GW) is comparable to that of Spain (World Bank, 2008). Generating capacity has been stagnant and growth rates are about half of those in other developing countries. The World Bank (2008a) argues that Africa's overstretched electricity systems have become exceedingly vulnerable to supply shocks, resulting in widespread outages and load shedding.

The above leads to the conclusion that none of the countries in SADC are performing well enough in the supply and distribution of electricity to effect significant shifts in their populations towards utilising modern fuels, even at present prices. Furthermore, price increases are inevitable as the regional electricity supply crunch worsens; effects of longterm global oil price risks sink in, and the real environmental cost of fossil fuels are factored into ener- 
gy prices. There is no alternative for most of the wood fuel dependant population who continue to use ever scarcer and more expensive biomass, and energy access and security issues are set to become crucial and possibly critical in the future.

If this is the stark reality of household energy use in SADC, is there any hope of improving matters for poor consumers? The paper will argue that the exponential growth in technology development currently being experienced will result in appliances for thermal applications becoming available, aimed at the low-income market and utilising fuels that were traditionally regarded as low on the energy ladder (like biomass and crop residues). A range of high quality, highly efficient products is posed to come on to the market supported by large international companies cooperating closely to realise the goal of delivering these products at extremely affordable prices, utilising their existing distribution channels and networks. These high quality appliances will contribute to a paradigm shift in thinking on energy supply to low-income households: the goal of exclusive electricity use for all energy requirements can be abandoned in favour of a model delivering small amounts of high-quality electricity for non-thermal applications coupled to the use of modern, efficient and affordable technologies for thermal applications.

The following section will describe the technological advances in more detail as well as highlight the other factors contributing to the paradigm shift in low-income household energy supply.

\section{Converging opportunities 3.1 Accelerated technology development capacity}

'The Law of Accelerating Returns' (Kurzweil, 2001) postulates that, technology is progressing at an exponential rate. The law, put simply, means that the larger the quantity of (in this case) technology, the faster it grows. If the notion of exponential growth is made applicable to the growth of knowledge, it can be said that as knowledge accumulates to a certain point, the pace at which discoveries are made starts accelerating, for example, micro chip capacity, computer processor capacity and cell phone technology. Importantly, when knowledge is focused to address a specific problem, advances can be even quicker and more impressive.

What this means for energy efficient appliances and improved basic energy delivery, is that, as more improved appliances are being developed, and as technology improves, more energy efficient appliances of higher quality will be available in the market more quickly, forever changing the face of basic energy delivery to low-income households. The paper therefore argues that the exponential growth in technology development witnessed over the last five to 10 years is also occurring in the field of ener- gy efficient appliances and is contributing to a paradigm shift in basic energy delivery to low-income households.

Examples of the exponential growth within the field of knowledge concerning household energy technologies abound. The photovoltaic lighting industry benefited enormously with the development of light-emitting diode (LED) lights. According to Zhou and Narendran (2005), PV systems produce direct current (d.c.) power, which cannot be used efficiently or reliably to operate many traditional light sources without conversion and battery storage, which also introduce efficiency losses. LEDs, however, can work effectively off d.c. power. The availability of LED lights therefore, reduced the cost of supplying PV solutions to low-income households and businesses significantly.

The paper will argue that the availability of LEDs will enable the supply of high-quality, affordable energy for lighting in households and small businesses while high quality appliances powered by traditionally low-order energy sources such as wood, dung and crop wastes will supply reliable, high quality thermal energy for cooking and heating applications. The combination of the two technologies, coupled with the challenges experienced in the electricity supply sector in SADC countries will lead to a final abandonment of the energy ladder concept and the notion of grid electricity being the only viable energy supply option. But what do the new promising appliances look like and how do they work?

For example, a collaborative venture between UK universities resulted in the development of the 'Score Stove' (www.score.ukcom). The Score stove, based on thermoacoustics technology is a wood, dung or gas burning stove that can cook food, generate enough electricity to charge batteries, for example, cell phones and has a built in fridge. To use the SCORE stove, wood is placed inside the stove and burned. The fire heats compressed air, which begins to vibrate and produce sound waves. The sound waves vibrate a diaphragm located at the end of a pipe. The diaphragm is attached to a coil of metal wires that sit inside a magnet. As the wire coil vibrates it generates an electrical current, which is captured by wires and converted to the proper voltage.

A prototype has been build and plans are to field test the unit in communities during 2009. The target is to sell the product for $\$ 50$ (all costs, transportation and profits included) to the target market, at a rate of 1 million units per year.

Researchers at Phillips designed a wood burning stove that can save up to $80 \%$ of fuel and also drastically reduce air pollution. The secret of the many benefits of the stove is an electronically controlled fan forcing air through the stove, leading to higher temperatures and a better fuel to air ratio. This 


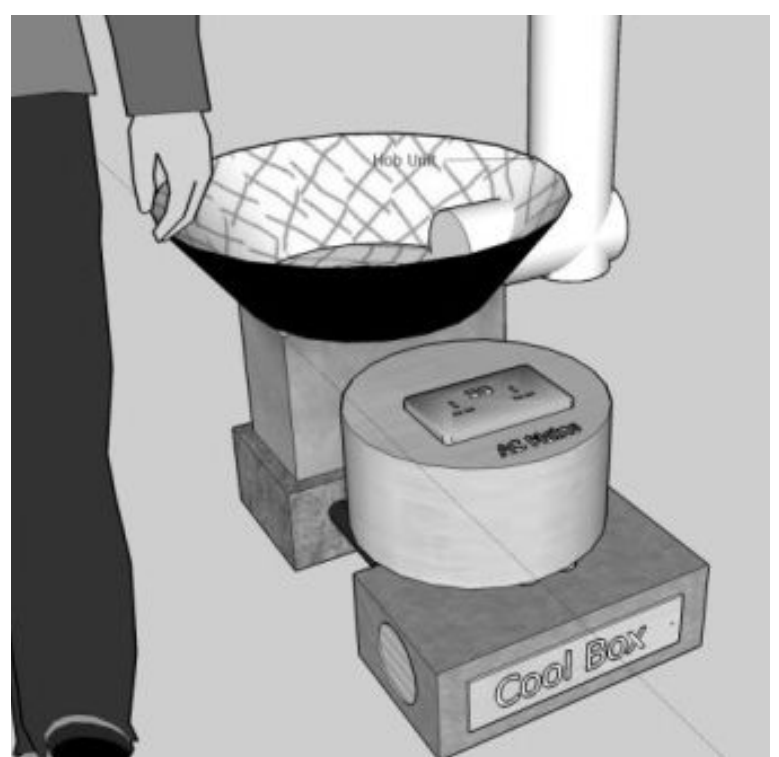

Figure 1: A graphic illustration of the |Score stove

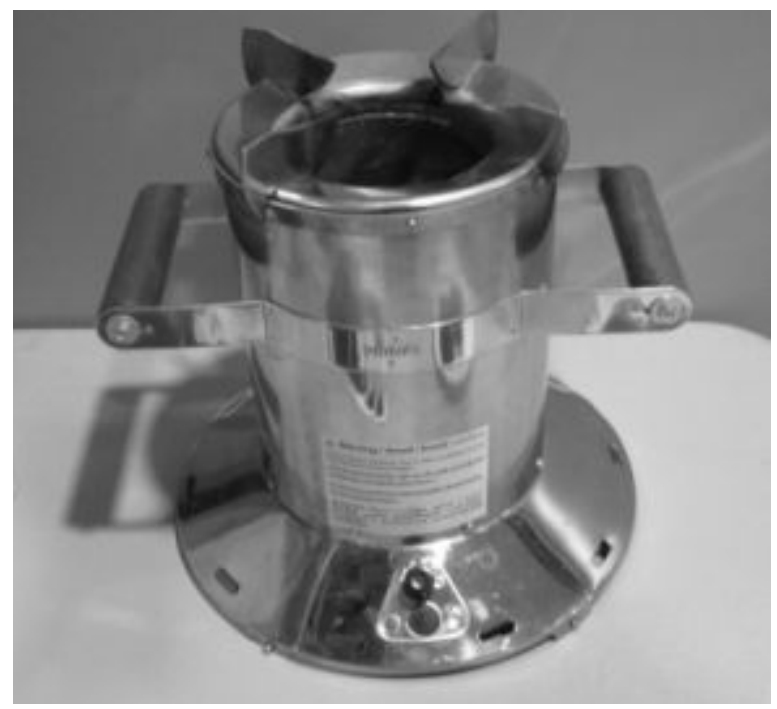

Figure 2: The Philips Woodstove

results in cleaner burning and more efficient use of fuel. A thermoelectric generator using the heat from the burning wood generates electricity for the fan. Apart from ensuring autonomy from electricity supplies, the generator can also power external equipment like radios or lighting. Philips Research also optimized the construction of the stove for low thermal mass and good insulation. This ensures that the stove takes less energy to heat up; decreasing the time to get to cooking temperature, and makes sure the stove loses less of its heat to the surroundings (www.research.philips.com).

Alders (2007) reported that in comparison with traditional stoves, the Philips Woodstove reduces $94 \%$ of carbon monoxide emissions, $93 \%$ of particular matter and results in a $45 \%$ wood saving. Some challenges however, remain and on-going research focuses on improving the life-time of the stove, reducing the currently required bi-annual

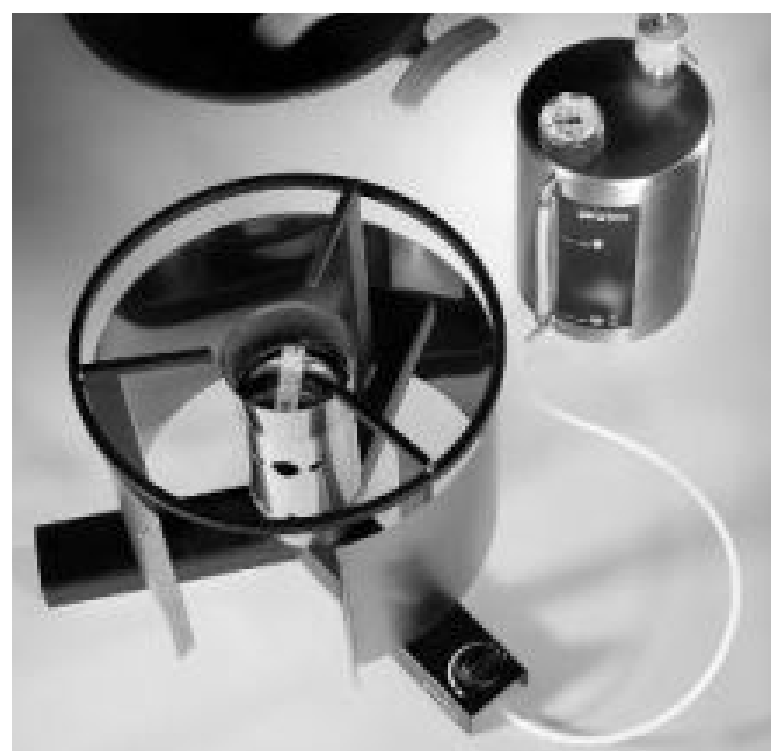

Figure 3: The Protos stove developed by |Bosch and Siemens

services and improving handling and safety without additional cost.

Bosch and Siemens Home Appliances Group in Munich, Germany, developed the Protos stove which uses plant oil as a fuel. The technology was originally developed at the University of Hohenheim in Germany, and collaboration involved various institutes like the German universities of Karlsruhe, Stuttgart, Hohenheim, Munich and the Leyte State University in the Philippines. The functioning of the Protos stove is similar to the functioning of a paraffin (kerosene) pressure stove but for the combustion of plant oil, a completely new burner was developed. The burner enables a diverse range of crude or refined plant oils like coconut or jatropha or oil esters and kerosene to be used.

The Protos stove has been tested since 2004 in the Philippines and in 2006, a field test was also carried out in Arusha, Tanzania. Activities continue to optimise the technology and production of a small series of cookers is planned for 2008 (www.pciaonline.org).

The abovementioned technologies represent a true breakthrough, not only in the technology itself, but in the partnerships labouring to bring the technology to market.

Exponential growth, however, is not only applicable to technology per se, but also in the way in which technological diffusion is taking place. The World Bank (2008b) notes that the pace at which technology spreads between countries is accelerating -whereas a new technology in the 1800's could take as long as 100 years to reach $80 \%$ of the world's countries, for a new technology to reach $80 \%$ of the world's countries now takes less than 20 years. The World Bank (2008b) further explains that on average, technology is advancing more rap- 
idly among low-income countries than in middle- or high income countries but notes that this could be attributed to a situation of catch-up.

It is further noted that virtually all technological progress in developing countries comes from the adoption and adaptation of pre-existing technologies, often developed in high-income countries. The analysis holds true for the development of new technologies for the domestic energy market - most technologies are being developed in high-income countries, aimed for the market in low-income countries, maximising the benefits afforded by adequate $\mathrm{R} \& \mathrm{D}$ funding, collaborating expertise and investment funds available in developed countries.

\subsection{Big business interest in the bottom of the pyramid}

The phrase 'the bottom of the pyramid' was coined by C.K Prahalad in his 2004 book titled: The Fortune at the bottom of the pyramid. Prahalad (2004) theorised that the approximate 4 billion people living on less than $\$ 2$ per day are not an economic lost case but present tremendous benefits to multi-national companies who choose to serve these markets in ways responsive to their needs. Prahalad (2004) proposed that businesses, governments, and donor agencies stop viewing the poor as victims and instead start seeing them as resilient and creative entrepreneurs as well as valuedemanding consumers. Business Report (2007) notes that the world's four billion poor are estimated to have $\$ 5$ trillion of annual purchasing power parity, a measure that tries to translate local buying strength into another currency based on common goods.

Thinking of low-income households as viable customers challenges product suppliers to offer products to the market that are innovative, packaged and distributed appropriately and are affordable, either per se or through the supply of credit to enable customers to buy the product. Interesting examples ${ }^{2}$ are Hindustan Lever supplying a shampoo in India that works best in cold water, Unilever in South Africa that supplies Five Roses Tea (a very desirable brand of tea) in a package containing only 10 teabags which makes it affordable and off course, the explosion of cell phone ownership and use, made possible by innovative pre-payment options in countries like South Africa where $41 \%$ of adults in South Africa use a cell phone, $60 \%$ of households own one and on average people spend $3 \%$ of their income on cell phones (AMPS, 2005). The paper argues that businesses are employing lessons learned through marketing of fast moving consumer products, to make innovative energy products available to the same customers.

The ideas formulated in the Bottom of the Pyramid (BoP) literature sparked debate, most noteably from Karnani (2006) who argued that the private sector should view the poor as producers and emphasize buying from them, rather than only selling to them. Concerns were raised that corporate $\mathrm{BoP}$ strategies represent nothing more than veiled attempts to 'sell to the poor', as though simply turning the poor into 'consumers' will address the fundamental problems of poverty and sustainable developments (Karnani, 2006, quoted in Simanis and Hart, 2008). Simanis and Hart (2008) argue that if the enterprise-based approach to poverty alleviation is to flourish, BoP approaches need to move from the idea of 'selling to the poor', to the concept of 'business co-venturing'.

Although it is beyond the scope of the paper to describe the technical aspects of the new approach in detail, it is clear that established organisations and 'big business' are currently interested in developing second generation cooking appliances to lowincome markets, and are following the suggested principles contained in second-generation BoP thinking, such as developing BoP business partners, deep dialogue with target markets, building shared commitments and creating mutual value in the products. ${ }^{3}$ For example, Bosch Siemens have tested the Protos technology extensively over a period of years to ensure adequate feedback from users.

A number of established, respected organisations such as Bosch, Siemens and Philips are interested to bring their know-how, resources, structures and experience to bear on the social and environmental challenges caused by low-income household energy use. We believe that the new energy and focus of resources from private business, combined with opportunities created by carbon instruments and public sector support will tip the scales and see a revolution in the availability of high-quality, durable energy appliances for low-income households.

\subsection{Carbon instruments}

The global carbon markets present a good opportunity for improved cooking stove programs given the significant contribution of such programs towards both greenhouse gas emission reductions and sustainable development impacts. In February 2008, the CDM Executive Board (EB) approved two small-scale methodologies pertaining to non-renewable biomass. Importantly, one of them is for the improvement in efficiency of non-renewable biomass end-use. This is particularly significant as it allows improved cooking stove programs to access the regulated carbon markets through the Clean Development Mechanism (CDM) and associated mechanisms such as the European Union Emissions Trading Scheme (EU ETS).

However, the voluntary carbon market holds the most potential in terms of carbon funding, given that high transaction and other fixed costs associated with the more stringent and bureaucratic regu- 
lated CDM market are avoided. This is important because small-scale projects such as improved cooking stove programs do not often generate large amounts of verifiable emission reductions or at least not enough to have a significant profit margin. There are also high quality standards available in the voluntary market such as the Gold Standard and the Voluntary Carbon Standard that ensure that the carbon product being delivered into the market is of high reputability and from genuinely and accurately verified emissions reductions.

Importantly, higher quality verification standards for Verified Emission Reduction Certificates (VER's) mean a higher rate for your verified product, possibly between 5-15 euros, depending on the standard imposed and the resulting VER product. Furthermore, financing in the voluntary carbon market can be provided up front even before the first VER is received. This is highly dependent on the ability of the respective agency to reduce the risk associated with their carbon product. It makes the respective product more accessible to many VER buyers in the market and allows an agency to demand a significant and profitable rate for their product. But how does involvement in the carbon markets and carbon financing provide opportunities for transformation in the household energy sector?

From a financial point of view, the funding received from sold VER's or other carbon credits can be significant and can be used to reduce the end-price of appliances, alternative financing mechanisms or as an alternative revenue stream parallel to that of donor funding.

\subsection{Public sector influence and support}

With the proverbial shrinking of the world and the growth of the global village, development problems are increasingly global problems. Climate change, caused by specific energy use patterns affect the planet, not just an isolated community, overexploitation of biomass resources causes environmental degradation affecting whole regions, and bad air quality caused by burning coal or wood affects whole cities and not just the poor residential areas using the fuels.

With the growing realisation of the global nature of current development problems, came the growing recognition of the inability of traditional instruments to effect development and change. Simanis and Hart (2008) argue that despite five decades and over $\$ 2$ trillion dollars spent on foreign aid, the top-down prescription of the post World War II development regime have proven ineffective. The adoption of the United Nations Millennium Declaration and the formulation of the Millennium Development Goals (MDG's) in 2000 provided much needed focus and re-alignment of donors to tackle the development problems of the world.
Although energy is not specifically mentioned in the MDG's, it has been recognized that energy services are essential to both social and economic development and that much wider and greater access to energy services is critical to achieve the MDGs (Modi et al., 2005). To ensure that the MDGs are achieved Modi et al. (2005) recommend that energy considerations be included in national MDG strategies and development planning frameworks. A number of recommendations are closely aligned with the main arguments of the paper, for example:

- Adopt legal and regulatory frameworks that will provide incentives for effective partnerships among government institutions, private sector utilities and other operators and community organizations;

- Allow for a wide range of technologies to ensure safe technical solutions in service provision;

- Improve the affordability, availability and safety of cooking fuels and practices;

- Support efforts to develop and adopt the use of sustainable biomass and biomass-derived fuels, improved stoves and practices that reduce exposure to harmful emissions;

- Increase the efficiency of conversion of biomass to biomass-derived cleaner fuels;

- Adopt strategic, institutional and financial measures to ensure wider access for households and small businesses in urban and peri-urban settings to services such as illumination and power, information and communication technology, refrigeration and other beneficial uses;

- Take a flexible approach to selecting from a wide range of technologies as well as a wide range of institutional structures for the delivery of energy services.

The targets outlined in the MDG's forced donors and recipient countries to examine the impact and effectiveness of aid packages to developing countries, ultimately resulting in the Paris Declaration on Aid Effectiveness in 2005. The Paris Declaration formulated indicators and targets of progress towards increased effectiveness in development assistance. The challenge for the multilateral and bilateral donors, as well as partner countries, is to harmonize their operational policies, procedures, and practices and to align their support with country-owned poverty reduction strategies or other development frameworks. Harmonization has the potential to not only reduce the costs of aid, but to increase the benefits of aid. The cumulative effect is expected to change the way development business gets done in the 21st century.

Not only are the ways changing in which the public sector co-operate, but change is also evident in the way in which public and private sector partners are co-operating. An emerging willingness of governments to create the best enabling environments for private sector operators are evident, for 
example, the role of the government played in Brazil in developing the biofuels sector in the country, and the role of the German government to develop the renewable energy industry in Germany.

In summary, increased donor cooperation and harmonization will lead to more effective development assistance, in turn contributing to the achievement of the MDGs. The critical role of energy in the MDGs is increasingly realized and contributes to the favourable environment for a paradigm shift in approaching household energy supply options.

\section{Conclusion}

The paper has attempted to build a case for a new approach by development agencies to providing support for delivering basic energy to low-income households in developing countries. This approach requires breaking out of a more traditional mould and extending the PPP relationship to ensure that the voice of the people who are meant to benefit is also heard.

There is evidence that the private sector, for whatever motives, is particularly good at this and that development agencies need to respond positively and actively to the convergence of four tracks: accelerated technology development capacity; the interest of big business at the bottom of the pyramid; the growth of global carbon markets; and the potential for public sector interest and support.

\section{Notes}

1. The Southern African Development Community (SADC) is an alliance of southern African states. The member states are Angola, Botswana, the Democratic Republic of Congo, Lesotho, Mada-gascar, Malawi, Mauritius, Mozambique, Nam-ibia, South Africa, Swaziland, United Republic of Tanzania, Zambia and Zimbabwe (www.sadc. int)

2. The Business Day (June 4, 2007) article 'Corporate giants aim to tap bottom of the bottom of the pyramid' provides detail on various successful examples of how firms developed new, affordable products and devised novel ways of selling them.

3. The principles of the next generation BoP strategy is outlined in Simanis and Hart (2008). Please refer to the publication for a detailed discussion of the listed principles.

\section{Bibliography}

Alders, J. The Philips Woodstove. From a research prototype to a commercial business proposition. Presentation made at the 2007 ETHOS Conference, Kirkland 26 -28 January 2007.

All Media and Products Survey (AMPS). 2005. The South African Research Foundation, Johannesburg.

Balmer, M. 2007. Is wood fuel use sustainable or unsus- tainable in Lesotho? Results from a desk top analysis. GTZ Programme for Biomass Energy and Conservation (ProBEC):Johannesburg.

Business Report. 2007. Corporate giants aim to tap bottom of the pyramid. June 4, 2007. www.busrep.co.za

Clancy, J. 2004. Urban poor livelihoods: Under-standing the role of energy services. DFID KaR R8348.

Karnani, A. G. 2006. 'Fortune at the Bottom of the Pyramid: A Mirage'. Ross School of Business Paper No. 1035.

Kruger, G. 2006. Firebomb kerosene stoves without social bounds - addressing energy poverty in South Africa. Paper delivered at the Domestic Use of Energy Conference, Cape Town, 2006.

Kurzweil, R. 2001. The law of accelerating returns. Published on KurzweilAI.net March 7, 2001

Litovsky, A. 2007. Energy poverty and political vision. Paper compiled for the workshop on Energy and Democratic Leadership: Promoting Access to Energy for Poverty Reduction held in Santander, Spain on 20-21 August 2007.

Modi, V; McDade, S; Lallement, D and Saghir, J. 2005. Energy services for the Millennium Development Goals. Acheiving the Millennium Development Goals. The World Bank: Washington D.C.

Pachauri, S. and Spreng, D., 2003. Energy use and energy access in relation to poverty. CEPE Working Paper No.25. Centre for Energy Policy and Economics: Zurich.

Prahalad, C.K. 2004. The fortune at the bottom of the pyramid. Wharton School Publishing: University of Pennsylvania, Pennsylvania.

Prasad, G., 2006. Energy sector reform and the pattern of the poor: Energy use and supply. A four country study Botswana, Ghana, Honduras and Senegal. The World Bank: Washington, D.C.

Price, L., de la Rue du Con, S., Sinton, J., Worrell, E., Nan, Z., Sathaye, J. and Levine, M., 2006. Sectoral trends in global energy use and green house gas emissions. Lawrence Berkeley National Laboratory: University of California.

Pringle, C. 2008. Massive fuel price hike 'certainly not looking good' - economists. Engineering News. www.engineeringnews.co.za

Simanis, E and Hart, S. 2008. The base of the pyramid protocol: towards the next generation BoP strategy. Second edition. Cornell University: New York.

Website: www.picaonline.org.

Website: www.research.philips.com.

Website: www.sadc.int.

Website: www.score.uk.com.

World Bank. 2008a. Africa's Power Supply Crisis: Unravelling the Paradoxes. World Bank Africa Region Sustainable Development Department: Washington, DC.

World Bank. 2008b. Global Economic Prospects. Technology diffusion in the developing world. The World Bank: Washington D.C.

Zhou, Y and Narendran, N. 2005. Photovoltaic-powered light emitting diode lighting systems. Optical Engineering 44 (11), 111311 (November, 2005).

Received 1 September 2008; revised 13 May 2009 